\title{
Perfectionism and Eating Disorder among Nursing Students of Technical Institute at Benha University
}

\author{
Doha Abd-Elpaseer Mahmoud ${ }^{1}$, Fathyea Said Sayed Ibrahim ${ }^{2}$ \\ ${ }^{1}$ Lecturer of Psychiatric Nursing and Mental Health, Faculty of Nursing, Benha University Egypt \\ ${ }^{2}$ Assistant Professor of Psychiatric Nursing and Mental Health, Faculty of Nursing, Benha University, \\ Egypt \\ Corresponding Author: Doha Abd-Elpaseer Mahmoud \\ Email Address:dohamahmoud85@yahoo.com
}

\begin{abstract}
Background: Perfectionism has increased dramatically among young people, leading to negative effects such as eating disorders. Aim of the study: This study aimed to investigate the relation between perfectionism and eating disorder among nursing students of Technical Institute at Benha University. Research question: Is there a relation between perfectionism and eating disorder for nursing students of Technical Institute at Benha University. Design: A descriptive correlational design was utilized to achieve the aim of study. Setting: The study was carried out at the Technical Institute of Nursing at Benha University which affiliated to the Ministry of High Education. Sample: A convenient sample of second year nursing students (300) enrolled in first term, academic year 2019-2020 from the above mentioned setting. Tools: Tool (I):- A structured Interviewing Questionnaire, Tool (II):- Multidimensional Perfectionism Scale and Tool (III): Eating Disorder Scale. Results: Less than two-thirds of the studied students have normal body mass index, moderate perfectionism and more than half of them have moderate eating disorders. Conclusion: There was a highly positive correlation between total eating disorder and total perfectionism. Recommendations: Expand public awareness through mass media about perfectionism and its effect on eating disorder among university students.
\end{abstract}

Keywords: Perfectionism, Eating Disorder, Nursing Students. 


\section{Introduction}

Perfectionism is a complex personality characteristic with no universally accepted definition. It is sometimes viewed as a personality trait or symptom. It can also be understood as a process. Perfectionism can have positive and negative aspects. Having high standards can be an asset and in many cases, it can be helpful in attaining goals. However, perfectionism also exacts a cost and in the wrong situations, too much of it can be an impediment. The perfectionism associated with psychological problems is problematic and has been referred to as clinical (or dysfunctional) perfectionism. ${ }^{(\mathbf{1})}$

Perfectionism is a broad personality style characterized by a person's concern with striving for flawlessness and perfection and is accompanied by critical self-evaluations and concerns regarding others' evaluations. It is best conceptualized as a multidimensional and multilayered personality characteristic, Perfectionism drives people to be concerned with achieving unattainable ideals or unrealistic goals, often leading to many forms of adjustment problems such as depression, low self-esteem, suicidal thoughts and tendencies and a host of other psychological, physical, relationship, and achievement problems,. Recent data show that perfectionistic tendencies are on the rise among recent generations of young people. $^{(2)}$

Eating disorders are serious illnesses that are associated with severe medical complications and have significant psychiatric co-morbidity that could be life threatening. Include anorexia nervosa, bulimia nervosa, binge eating disorders, rumination disorders, avoidant/restrictive food intake disorders, and night-eating syndrome. (3) These disorders are more common in societies with excessive concern about appearance and weight. ${ }^{(4)}$

Anorexia nervosa is characterized by extreme food restriction and excessive weight loss, accompanied by the fear of being fat. The extreme weight loss often causes women and girls who have begun menstruating to stop having menstrual periods, a condition known as amenorrhea. (5) Bulimia nervosa is a disorder characterized by binge eating and purging, as well as excessive evaluation of one's self-worth in terms of body weight or shape, characterized by recurrent binge eating followed by compensatory behaviors such as purging (self-induced vomiting, eating to the point of vomiting, excessive use of laxatives/diuretics, or excessive exercise). Fasting and overexercising may also be used as a method of purging following a binge. (6) 
The cause of eating disorders is not clear. Both biological and environmental factors appear to play a role. Cultural idealization of thinness is believed to contribute. Eating disorders affect about 12 percent of dancers. (7) Those have experienced sexual abuse are also more likely to develop eating disorders. Some disorders such as pica and rumination disorder occur more often in people with intellectual disabilities. ${ }^{(8)}$

Eating disorders typically begin between 18 and 21 years of age, according to the National Eating Disorders Association (NEDA). The association estimates that between 10 and $20 \%$ of women and 4 to $10 \%$ of men in college suffer from an eating disorder, and rates are on the rise. Eating disorders in college students are serious, and can be life-threatening in some cases. $^{(9)}$

College students can be a time of a lot of excitement and stimulation and also a lot of stress. The stress of a college schedule, managing a new social context, and dealing with independent living can trigger re-emergent anxiety or, in some cases a new mental illness. Anxiety, social environment, and constantly exposed to the thin body ideal, that's a perfect storm convergence of factors that can drive a vulnerable individual into an eating disorder. Students in college are inundated with advertising, media messages, and misguided information about food, bodies, and health. Magazines targeted at college students showcase models with Body Mass Index well below healthy standards and extol the virtues of dieting ${ }^{(10)}$

The media shows models are society's standard of perfection, but the images are not even real; they are airbrushed. Competition and perfection, weight obsession, and poor coping skills through disordered eating take their toll on women of all ages, but those at the college student's level face an additional challenge: that of identity. College students create the space for individuals to experiment with who they are, what they want to do, and what it means to be an adult. It is typically a time of activated thought, critical thinking, challenging preconceived notions, freedom, and trial and error. ${ }^{(11)}$ Many college students especially with eating disorders do not like themselves. This is made worse with perfectionism. Today there are so many students who think they are not good enough, hating themselves and living a life of negativity. Perfectionism and eating disorders seem to be correlated, but the causality is not clear and don't know if one leads to the other or which comes first. Some research indicates that students with eating disorders and perfectionism often displayed perfectionist 
traits before their eating disorders $\operatorname{began}^{(\mathbf{1 2})}$.

\section{Significance}

In developed world, binge eating disorder affects about $1.6 \%$ of women and $0.8 \%$ of men in a given year ${ }^{(\mathbf{1 3})}$. Anorexia affects about $0.4 \%$ and bulimia affects about $1.3 \%$ of young women in a given year. Up to $4 \%$ of women have anorexia, $2 \%$ have bulimia, and $2 \%$ have binge eating disorder at some point in time ${ }^{(\mathbf{1 4})}$ College students are most affected by eating disorders. The university age is a time of complete change, change in environment, change of friends (15). Perfectionism tendencies have increased substantially among young people can cause maladaptive behavior that interfere with student's education and work in future (16). So, there is an important need for the researcher to conduct the study to investigate the perfectionism and eating disorder among nursing students of Technical Institute at Benha University.

\section{Aim of the study}

The present study aimed to investigate the relation between perfectionism and eating disorder among nursing students of Technical Institute at Benha University.

\section{Research questions}

1- What is the students ' level of perfectionism?

2- What is the students ' level of eating disorder?
3- Is there a relation between perfectionism and eating disorder among nursing students of Technical Institute at Benha University?

\section{Subject and methods}

\section{Research Design}

A descriptive correlational design will be utilized to achieve the aim of this study.

\section{Study Setting:-}

The study was carried out at the Technical Institute of Nursing at Benha University which affiliated to the Ministry of High Education.

\section{Subjects}

A convenient sample of second year nursing students (300) enrolled in first term academic year 2019-2020, at the Technical Institute of Nursing, at Benha University and agree to participate after clarification purpose of the study .

\section{Tools of the data collection}

The aim of study was achieved through the use of the following three tools:

\section{Tool (I):- A structured Interviewing}

\section{Questionnaire Sheet}

It was designed by the researchers after reviewing related literature which consist of

(age, sex, height, weight, favorite sport, place of living, occupation, economical, marital status and family system). 
Tool

(II):-

Multi-dimensional

\section{Perfectionism Scale}

It was developed by Hewitt et al., (1991) (17) to assess student ' level of perfectionism. It consists of 44 statements from 4dimensions:-

First dimension: High standards of performance

which consist of 3 sub dimensions:

1- Self -oriented: consist of items 1, 5, $7,9,14,16,19,20$ and22.

2- Other -oriented: consist of items 34, 37,39 and 41.

3- Socially prescribed: consist of items 4 , $8,11,31,35,38$ and 40 .

Second dimension: Fear from failure which consists of items 3,10,12,24,33,42 and 44.

\section{Third dimension: General}

dissatisfaction which consists of items 17 , 23, 26, 28 and 36.

Fourth dimension: Feeling of low selfesteem which consists of items 2, 6, 13, 15, 18, 21, 25, 27, 29, 30, 32 and 43.

The scoring system: Student's responses were ranged from yes (3 point), sometimes( 2 point), no (1 point ) and the total score range from 44-132. A lower score means lower levels of perfectionism to students, while the higher score means higher levels of perfectionism to students. Level of perfectionism is considered high perception if the percent $\geq 75 \%$ (score $\geq$
99), moderate if the percent $60 \%-<75 \%$ (score 79 - < 99) and low if the percent < $60 \%$ (score $<79$ ).

\section{Tool (III): Eating Disorder Scale:-}

It was developed by Mohammad, $\mathbf{( 2 0 1 5 )}^{(\mathbf{1 8})}$ to assess student ' type of eating disorder. It consisted of consist of 28 statements from 2 dimensions:-

\section{First dimension: Anorexia nervosa}

which consists of items $1,2,4,5,7,9,10,13$, $14,16,19,20,21,22,24,25,26$ and 28

\section{Second dimension: Bulimia nervosa} which consists of items 3, $6,8,11,12,15,17,18,23$ and 27

\section{The scoring system:}

Student's responses were ranged from yes (3 point), sometimes ( 2 point), no (1 point) and the total score range from 28 84. A lower score means lower levels of eating disorder to students, while the higher score means higher levels of eating disorder to students.

Total score of anorexia nervosa range from 18-54.

Total score of bulimia nervosa range from 10-30.

Level of eating disorders high perception if the percent $\geq 75 \%$ (score $\geq 63$ ), moderate if the percent $60 \%-<75 \%$ (score $50-<$ 63 ) and low if the percent $<60 \%$ (score $<$ $50)$.

\section{Operational Design}


The operational design includes preparatory phase, validity, reliability, pilot study and field work.

\section{Preparatory phase}

An extensive literature related to the study area will be done including electronic dissertation, available books, and articles, doctoral dissertation, research and peer interaction and idea from external sources and periodicals to formulate knowledge base relevant to the study area and to get a clear picture of all aspect related to the research topic.

\section{Content Validity}

Before starting the data collection tools were translated into Arabic language and tested for its content validity by group of expertise in the psychiatric field to check the relevancy, clarity, comprehensiveness, and applicability of the questions. As a result of the jury, required modifications were done and the final form was developed.

\section{Reliability of tools}

Test-retest was repeated to the same sample of nursing students on two occasions and then compares the scores. The Cronbach's coefficient alpha of Multi-dimensional perfectionism scale is 0.68 for total score and eating disorder scale is 0.68 for total score

\begin{tabular}{|l|l|l|}
\hline Standardized tools & $\begin{array}{l}\text { Cronbach's } \\
\text { Alpha }\end{array}$ & $\begin{array}{c}\text { No of } \\
\text { Items }\end{array}$ \\
\hline $\begin{array}{l}\text { Multi-dimensional } \\
\text { perfectionism scale }\end{array}$ & $(0.68)$ & 44 items \\
\hline $\begin{array}{l}\text { Eating disorder } \\
\text { scale }\end{array}$ & $(0.68)$ & 28 items \\
\hline
\end{tabular}

Pilot study

After the tools have been designed, they were tested through a pilot study, which was done before embarking on the field work to check the clarity and feasibility of designed tools and to estimate the time needed to complete its items. a pilot study was carried out on $10 \%$ of the studied subjects (30) students who were excluded from the main study sample,. The purpose of the pilot study were to ascertain the clarity, applicability relevance and content validity of the tools, estimate the time needed to complete the sheet, and the necessary changes were undertaken.

\section{The results of the pilot study}

After conducting the pilot study, it was found that:

- The tools were clear and applicable; however, few modifications were made in rephrasing of some sentences in both Multi-dimensional perfectionism scale and eating disorder scale to be easier and more understandable.

- Tools were relevant and valid.

- No problem that interferes with the process of data collection was detected. 
- Following this pilot study the tools were made ready for use.

\section{Field work:-}

- Preparation of data collection was carried out through (10 weeks) two and half months from (beginning of October2019 to the half of December2019).

- The researchers were obtained permissions from the Director of Technical Institute of Nursing at Benha University to conduct the study.

- The field work included students, undergoing second year, first term in academic year 2019-2020 they consisted of 300 students.

- The researcher explained the purpose of the study, collected all students to be acquainted with them, and explained to them the objectives of the study and its expected outcomes.

- The time required to fill the questionnaires sheet was range from 25 to 30 minutes for Multi-dimensional perfectionism scale and from 20-25 minutes for eating disorder scale The filled forms were collected in time and revised to check their completeness to avoid any missing data

- The researchers filled in the questionnaire through two days/week(Wednesday \& Thursday), The average number of gathering questionnaires was between 1415 students per day and for 2 days/week (30 students /week/10 weeks).

\section{Administrative Design:}

A written letter was issued from the Dean of Faculty of Nursing, Benha University to the Director of Technical Institute of Nursing at Benha University to obtain the approval for data collection. The objectives and the nature of the study were explained and then it was possible to carry out the study with minimum resistance.

\section{Ethical consideration:}

- Approvals of students were obtained before data collection and after explaining the purpose of the study.

- Anonymity was assured as the filled questionnaire sheets were given a code number (not by names).

- The students were ensured that questionnaire sheet will be used only for the purpose of the study and will be discarded at the end of the study.

- The study maneuvers do not entail any harmful effects on participation.

- The students who participated in the study were informed about having the right to withdraw at any time without giving any reason.

\section{Statistical analysis}

Analysis of the data was carried out and the collected data was organized, coded, computerized and tabulated and analyzed 
by using (SSPS) programs version (20). Data analysis was accomplished by the use of number, percentage distribution chisquare (x2) test, to test the significance of some variance, significant $\mathrm{p}=<0.05$

\section{Results}

Table (1) shows that, socio-demographic data of the studied students. It clarified that two thirds $(66.7 \%)$ of the studied students, their age ranged from 20to less than 21 years. As regard to gender and residence $(79.0 \%, 86.3 \%$ respectively) the majority of the students were females and lives in rural area. Moreover majority of them were not working, have sufficient income, single and stable family status $(96.0 \%, 92.7 \%$, $76.7 \%$ and $85.6 \%$ ) respectively.

Figure (1): illustrates that distribution of the studied students regarding their favorite sport. It reflects that that nearly half $(48.7 \%)$ of the studied students were walking, While, the minority (6.0\%) of them were swimming as the favorite sport.

Table (2): reveals that, mean and standard deviation of the studied students regarding height, weight and body mass index were

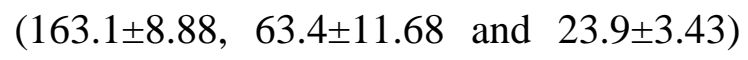
respectively.

Figure (2): demonstrates that distribution of the studied students regarding body mass index. It clarified that less than twothirds $(61.0 \%)$ of the studied students have normal body mass index while $4.7 \%$ only have obese.

Figure (3): shows that distribution of the studied students regarding total perfectionism. It reflects that less than twothirds $(61.3 \%)$ of the studied students have moderate perfectionism.

Table (3): reveals that, more than half $(56.0 \%)$ of the studied students have moderate anorexia nervous while two thirds $(66.7 \%)$ of them have bulimia nervosa.

Figure (4): shows that, more than half $(54.7 \%)$ of the studied students have moderate eating disorders, while the minority $(5.3 \%)$ of them has high eating disorders.

Table (4): reflects relation between total body mass index, total perfectionism and total eating disorders .It shows that, there were a statistical significant difference between total body mass index, total perfectionism and total eating disorders.

Table (5): represents relation between total perfectionism and socio-demographic characteristics of the studied students. It illustrates that, there was highly statistical significant difference between total perfectionism and socio-demographic characteristics such as sex, residence, family income and marital status while no statistical difference between total perfectionism and age, family status. 
Table (6): reports relation between total eating disorder and socio-demographic characteristics of the studied students. It reflects that, there was statistical significant difference between total eating disorders and socio-demographic characteristics such as sex and marital status while no statistical difference between total eating disorders and age, residence, family income and family status. Figure (5): represents correlation between total eating disorder and total perfectionism of the studied students .It illustrates that, there was highly positive correlation between total eating disorder and total perfectionism. 
Table (1): Frequency distribution of studied students regarding socio-demographic characteristics $(n=300)$

\begin{tabular}{|c|c|c|}
\hline $\begin{array}{c}\text { socio-demographic } \\
\text { characteristics }\end{array}$ & No & $\%$ \\
\hline \multicolumn{3}{|l|}{ Age/years } \\
\hline 19- & 86 & 28.7 \\
\hline $20-$ & 200 & 66.7 \\
\hline $21+$ & 14 & 4.6 \\
\hline \multicolumn{3}{|l|}{ Gender } \\
\hline Male & 63 & 21.0 \\
\hline Female & 237 & 79.0 \\
\hline \multicolumn{3}{|l|}{ Residence } \\
\hline Rural & 259 & 86.3 \\
\hline City & 41 & 13.7 \\
\hline \multicolumn{3}{|l|}{ Occupation } \\
\hline Working & 12 & 4.0 \\
\hline Not working & 288 & 96.0 \\
\hline \multicolumn{3}{|l|}{ Family income } \\
\hline Sufficient & 278 & 92.7 \\
\hline Not sufficient & 6 & 2.0 \\
\hline Sufficient and more & 16 & 5.3 \\
\hline \multicolumn{3}{|l|}{ Marital status } \\
\hline Married & 18 & 6.0 \\
\hline Single & 230 & 76.7 \\
\hline Engaged & 52 & 17.3 \\
\hline \multicolumn{3}{|l|}{ Family status } \\
\hline Un-stable & 2 & 0.7 \\
\hline Stable to somewhat & 41 & 13.7 \\
\hline Stable & 257 & 85.6 \\
\hline Total & 300 & 100.0 \\
\hline
\end{tabular}




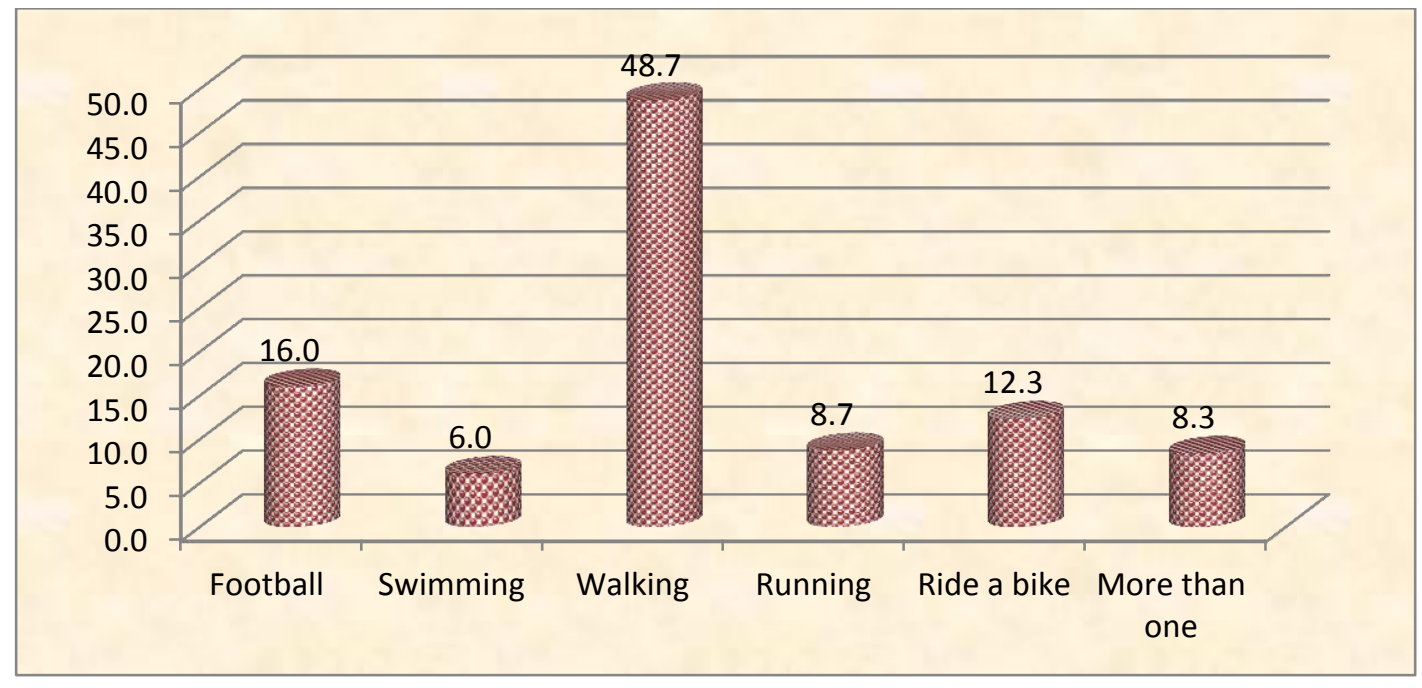

Figure (1): Frequency distribution of studied students regarding favorite sport $(n=300)$.

Table (2): Mean and standard deviation of the studied students regarding height, weight and body mass index $(n=300)$

\begin{tabular}{|l|c|c|c|}
\hline & Minimum & Maximum & Mean \pm SD \\
\hline Height & 138.00 & 186.00 & $163.1 \pm 8.88$ \\
\hline Weight & 8.00 & 93.00 & $63.4 \pm 11.68$ \\
\hline $\begin{array}{l}\text { Body mass } \\
\text { index }\end{array}$ & 16.40 & 34.90 & $23.9 \pm 3.43$ \\
\hline
\end{tabular}

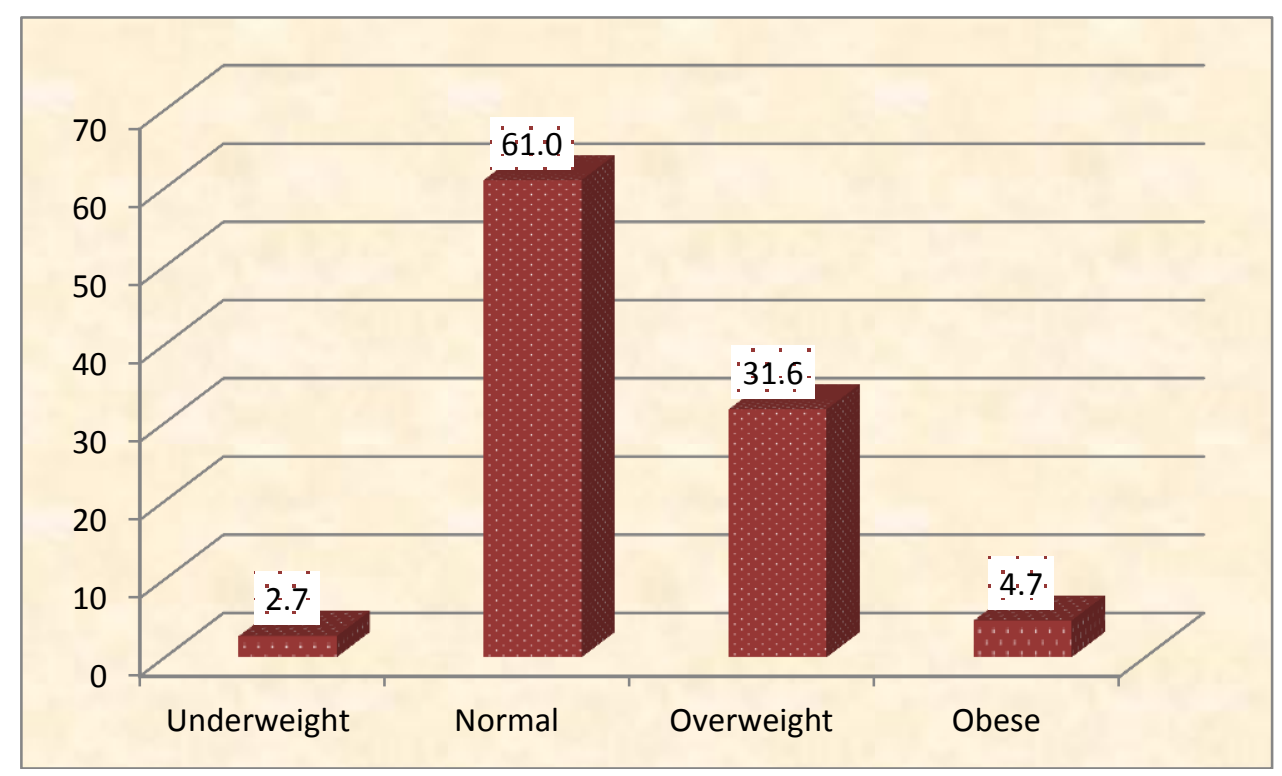

Figure (2): Frequency distribution of studied students regarding body mass index $(n=300)$ 


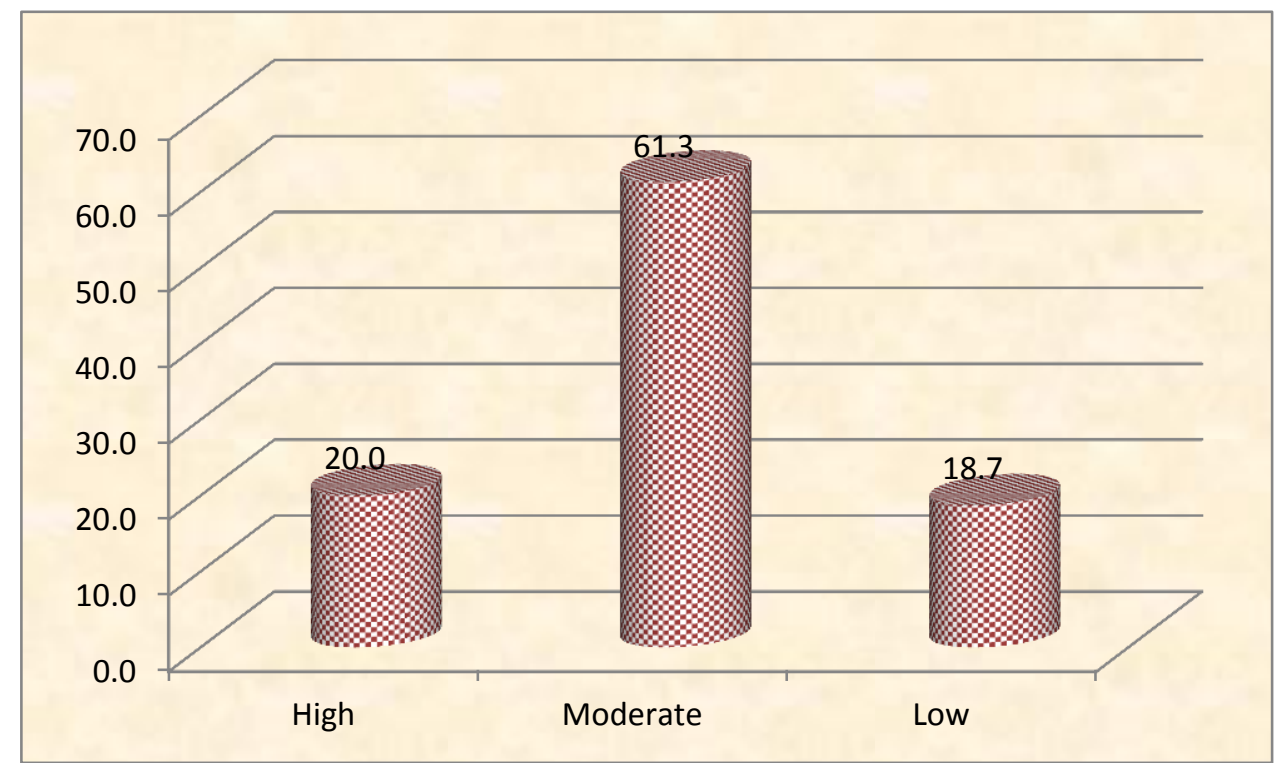

Figure (3): Frequency distribution of studied students regarding total perfectionism( $\mathrm{n}=300)$.

Table (3): Frequency distributions of studied students regarding anorexia nervous and bulimia nervosa $(n=300)$.

\begin{tabular}{|l|c|l|l|l|l|l|}
\hline \multirow{2}{*}{} & \multicolumn{2}{|c|}{ High } & \multicolumn{2}{c|}{ Moderate } & \multicolumn{2}{c|}{ Low } \\
\cline { 2 - 8 } & No & $\%$ & No & $\%$ & No & $\%$ \\
\hline Anorexia nervosa & 14 & 4.7 & 168 & 56.0 & 118 & 39.3 \\
\hline Bulimia nervosa & 20 & 6.7 & 200 & 66.7 & 80 & 26.6 \\
\hline
\end{tabular}

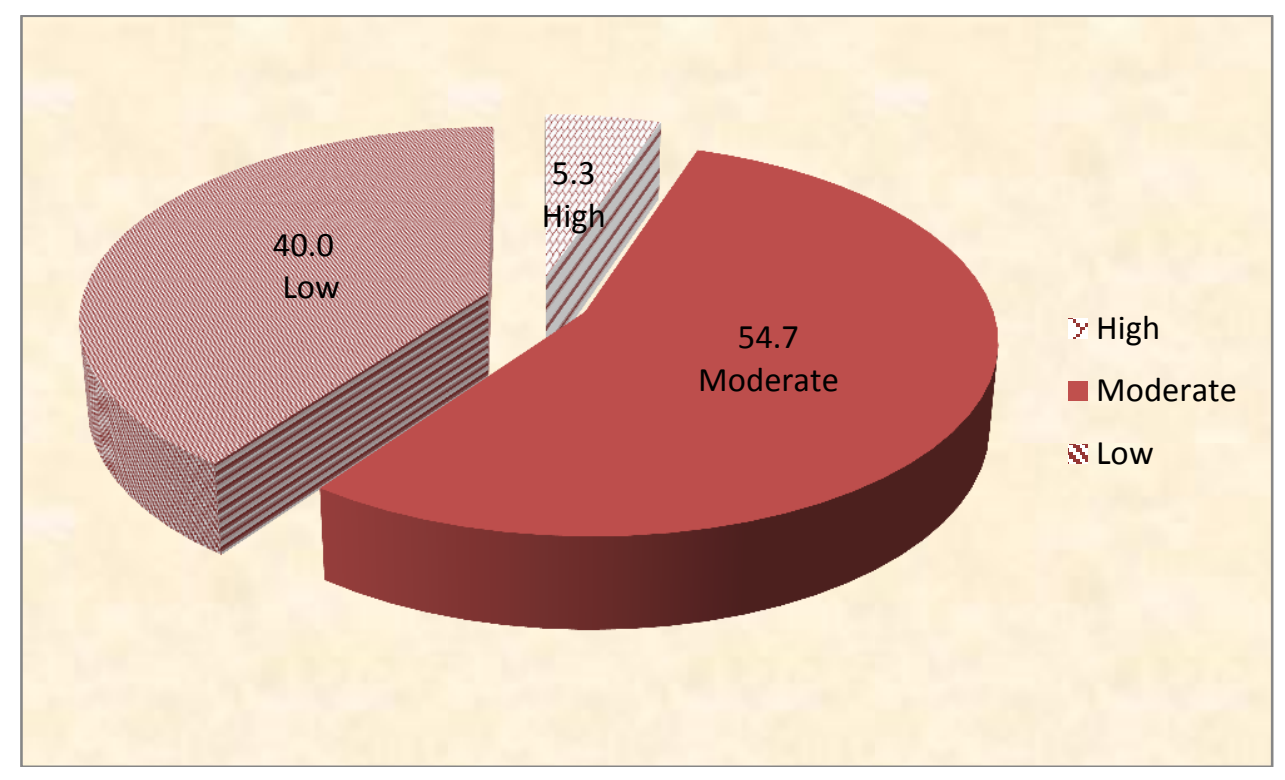

Figure (4): Frequency distribution of studied students regarding total eating disorders $(n=300)$. 
Table (4): Relation between total body mass index, total perfectionism and total eating disorders $(\mathrm{n}=300)$.

\begin{tabular}{|c|c|c|c|c|c|c|c|c|c|c|}
\hline & \multicolumn{8}{|c|}{ Body mass index } & \multirow[t]{2}{*}{$\mathbf{X}^{2}$} & \multirow[t]{2}{*}{ p-value } \\
\hline & \multicolumn{2}{|c|}{ Underweight } & \multicolumn{2}{|c|}{ Normal } & \multicolumn{2}{|c|}{ Overweight } & \multicolumn{2}{|c|}{ Obese } & & \\
\hline \multicolumn{11}{|c|}{$\begin{array}{l}\text { Total } \\
\text { Perfectionism }\end{array}$} \\
\hline \multirow[b]{2}{*}{ Low } & No & $\%$ & No & $\%$ & No & $\%$ & No & $\%$ & \multirow[t]{4}{*}{15.82} & \multirow[t]{4}{*}{$0.015^{*}$} \\
\hline & 0 & 0.0 & 32 & 17.5 & 20 & 21.1 & 4 & 28.6 & & \\
\hline $\begin{array}{l}\text { Moder } \\
\text { ate }\end{array}$ & 8 & 100.0 & 103 & 56.3 & 65 & 68.4 & 8 & 57.1 & & \\
\hline High & 0 & 0.0 & 48 & 26.2 & 10 & 10.5 & 2 & 14.3 & & \\
\hline \multicolumn{11}{|c|}{$\begin{array}{l}\text { Total Eating } \\
\text { disorders }\end{array}$} \\
\hline Low & 5 & 62.5 & 82 & 44.8 & 31 & 32.6 & 2 & 14.3 & \multirow[t]{3}{*}{16.33} & \multirow[t]{3}{*}{$0.012 *$} \\
\hline $\begin{array}{l}\text { Moder } \\
\text { ate }\end{array}$ & 3 & 37.5 & 95 & 51.9 & 54 & 56.8 & 12 & 85.7 & & \\
\hline High & 0 & 0.0 & 6 & 3.3 & 10 & 10.6 & 0 & 0.0 & & \\
\hline
\end{tabular}

(*) significant at $\mathrm{p}<0.05$.

Table (5): Relation between total perfectionism and socio-demographic characteristics of studied students $(n=300)$.

\begin{tabular}{|c|c|c|c|c|c|c|c|c|}
\hline \multirow{2}{*}{$\begin{array}{l}\text { socio- } \\
\text { demographic } \\
\text { characteristics }\end{array}$} & \multicolumn{6}{|c|}{ Total perfectionism } & \multirow[b]{2}{*}{$\mathbf{X}^{2}$} & \multirow[b]{2}{*}{ p-value } \\
\hline & \multicolumn{2}{|c|}{ Low $(n=56)$} & \multicolumn{2}{|c|}{ Moderate $(n=184)$} & \multicolumn{2}{|c|}{ High $(n=60)$} & & \\
\hline Age & No & $\%$ & No & $\%$ & No & $\%$ & \multirow{4}{*}{9.07} & \multirow{4}{*}{$0.59 \mathrm{n} . \mathrm{s}$} \\
\hline $19-$ & 14 & 25.0 & 48 & 26.1 & 24 & 40.0 & & \\
\hline $20-$ & 42 & 75.0 & 124 & 67.4 & 34 & 56.7 & & \\
\hline $21+$ & 0 & 0.0 & 12 & 6.5 & 2 & 3.3 & & \\
\hline \multicolumn{9}{|l|}{ Sex } \\
\hline Male & 2 & 3.6 & 35 & 19.0 & 26 & 43.3 & \multirow[t]{2}{*}{28.7} & \multirow{2}{*}{$<0.001 * *$} \\
\hline Female & 54 & 96.4 & 149 & 81.0 & 34 & 56.7 & & \\
\hline \multicolumn{9}{|l|}{ Residence } \\
\hline Rural & 48 & 85.7 & 151 & 82.1 & 60 & 100.0 & \multirow{2}{*}{12.35} & \multirow{2}{*}{$0.002 *$} \\
\hline City & 8 & 14.3 & 33 & 17.9 & 0 & 0.0 & & \\
\hline \multicolumn{9}{|l|}{ Family income } \\
\hline Sufficient & 54 & 96.4 & 172 & 93.4 & 52 & 86.7 & \multirow{3}{*}{13.12} & \multirow{3}{*}{$0.011 *$} \\
\hline Not sufficient & 0 & 0.0 & 6 & 3.3 & 0 & 0.0 & & \\
\hline $\begin{array}{l}\text { Sufficient and } \\
\text { more }\end{array}$ & 2 & 3.6 & 6 & 3.3 & 8 & 13.3 & & \\
\hline \multicolumn{9}{|l|}{ Marital status } \\
\hline Married & 6 & 10.7 & 10 & 5.4 & 2 & 3.3 & \multirow{3}{*}{9.91} & \multirow{3}{*}{$0.042 *$} \\
\hline Single & 38 & 67.8 & 138 & 75.0 & 54 & 90.0 & & \\
\hline Engaged & 12 & 21.5 & 36 & 19.6 & 4 & 6.7 & & \\
\hline \multicolumn{9}{|l|}{ Family status } \\
\hline Un-stable & 0 & 0.0 & 2 & 1.1 & 0 & 0.0 & \multirow{3}{*}{5.9} & \multirow{3}{*}{$0.20 \mathrm{n} . \mathrm{s}$} \\
\hline $\begin{array}{l}\text { stable to } \\
\text { somewhat }\end{array}$ & 6 & 10.7 & 31 & 16.8 & 4 & 6.7 & & \\
\hline stable & 50 & 89.3 & 151 & 82.1 & 56 & 93.3 & & \\
\hline
\end{tabular}

(n.s ) Not Statistically Significant (*) Statistically Significant at $\leq 0.05 \quad$ (**) Highly Statistically Significant at $\leq 0.001$ 
Table (6): Relation between total eating disorder and socio-demographic characteristics of studied students $(n=300)$.

\begin{tabular}{|c|c|c|c|c|c|c|c|c|}
\hline \multirow{3}{*}{$\begin{array}{l}\begin{array}{l}\text { socio- } \\
\text { demographic } \\
\text { characteristics }\end{array} \\
\text { Age }\end{array}$} & \multicolumn{6}{|c|}{ Total eating disorder } & \multirow{2}{*}{$\mathbf{X}^{2}$} & \multirow{3}{*}{ p-value } \\
\hline & \multicolumn{2}{|c|}{ Low $(n=120)$} & \multicolumn{2}{|c|}{ Moderate (n=164) } & \multicolumn{2}{|c|}{ High $(n=16)$} & & \\
\hline & No & $\%$ & No & $\%$ & No & $\%$ & \multirow{4}{*}{4.01} & \\
\hline $19-$ & 36 & 30.0 & 44 & 26.8 & 6 & 37.5 & & \multirow[t]{3}{*}{$0.40 \mathrm{n} . \mathrm{s}$} \\
\hline $20-$ & 80 & 66.7 & 112 & 68.3 & 8 & 50.0 & & \\
\hline $21+$ & 4 & 3.3 & 8 & 4.9 & 2 & 12.5 & & \\
\hline \multicolumn{9}{|l|}{$\operatorname{sex}$} \\
\hline Male & 26 & 21.7 & 30 & 18.3 & 7 & 43.8 & \multirow[t]{2}{*}{5.74} & \multirow[t]{2}{*}{$0.056^{*}$} \\
\hline Female & 94 & 78.3 & 134 & 81.7 & 9 & 56.2 & & \\
\hline \multicolumn{9}{|l|}{ Residence } \\
\hline Rural & 104 & 86.7 & 140 & 85.4 & 15 & 93.8 & \multirow[t]{2}{*}{0.88} & \multirow[t]{2}{*}{$0.64 \mathrm{n} . \mathrm{s}$} \\
\hline City & 16 & 13.3 & 24 & 14.6 & 1 & 6.2 & & \\
\hline \multicolumn{9}{|l|}{ Family income } \\
\hline Sufficient & 108 & 90.0 & 156 & 95.2 & 14 & 87.5 & \multirow{3}{*}{6.93} & \multirow{3}{*}{$0.14 \mathrm{n} . \mathrm{s}$} \\
\hline Not sufficient & 2 & 1.7 & 4 & 2.4 & 0 & 0.0 & & \\
\hline $\begin{array}{l}\text { Sufficient and } \\
\text { more }\end{array}$ & 10 & 8.3 & 4 & 2.4 & 2 & 12.5 & & \\
\hline \multicolumn{9}{|l|}{ Marital status } \\
\hline Married & 12 & 10.0 & 6 & 3.6 & 0 & 0.0 & \multirow[t]{3}{*}{12.23} & \multirow[t]{3}{*}{$0.016^{*}$} \\
\hline Single & 96 & 80.0 & 122 & 74.4 & 12 & 75.0 & & \\
\hline Engaged & 12 & 10.0 & 36 & 22.0 & 4 & 25.0 & & \\
\hline \multicolumn{9}{|l|}{ Family status } \\
\hline Un-stable & 0 & 0.0 & 2 & 1.2 & 0 & 0.0 & \multirow{3}{*}{6.69} & \multirow{3}{*}{$0.15 \mathrm{n} . \mathrm{s}$} \\
\hline $\begin{array}{l}\text { Stable to } \\
\text { somewhat }\end{array}$ & 10 & 8.3 & 28 & 17.1 & 3 & 18.8 & & \\
\hline Stable & 110 & 91.7 & 134 & 81.7 & 13 & 81.2 & & \\
\hline
\end{tabular}

(n.s ) Not Statistically Significant (*) Statistically Significant at $\leq 0.05$ 


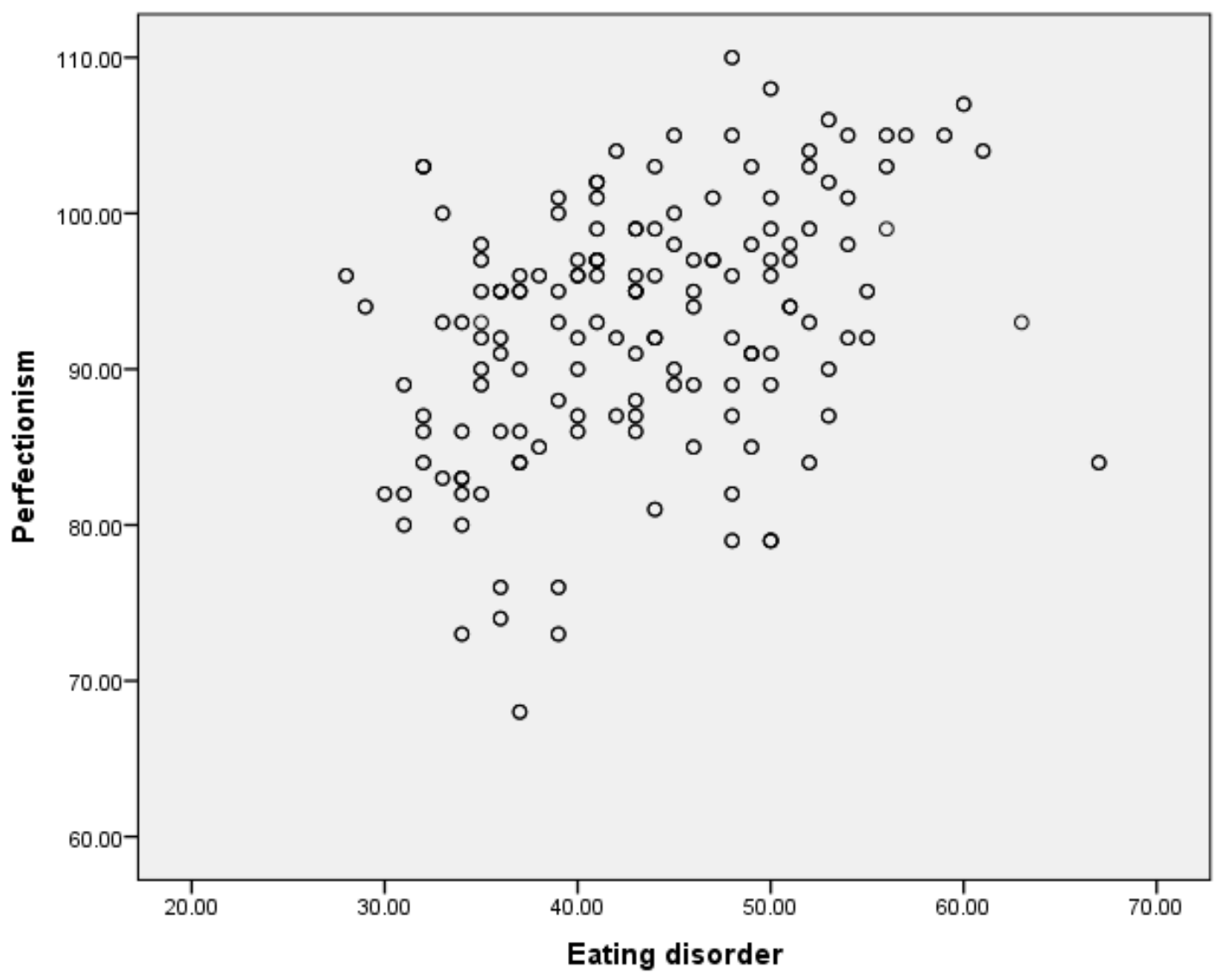

Figure (5): Correlation between total eating disorder and total perfectionism of the studied students $(n=300)$. 


\section{Discussion}

Perfectionism has been linked both conceptually and empirically to eating disorders. Hilde Bruch, a pioneer in the field of eating disorders, noted that eating disorder patients demonstrate "superperfection," and perfectionism related to the body is implied in a criterion common to both anorexia nervosa and bulimia nervosa, namely, that selfevaluation is overly reliant on [perfect] weight/shape. Empirically, there is evidence that perfectionism is elevated among those with eating disorders compared to healthy controls. Furthermore, recent intervention work in the area of eating disorders has focused on reducing perfectionism given its conceptualization as a maintenance factor. Thus, perfectionism appears to play a role in the etiology, maintenance, and treatment of eating disorders Fairburn etal. (2018) ${ }^{(19)}$. So, the present study aimed at investigate the relations between perfectionism and eating disorder for Nursing students.

The result of the present study revealed that two-thirds of the studied student's ages were from 20to less than 21 years. Highest percentages of the students were female. This is because it is the normal age for entering nursing institutions on Egypt and most of them are female.These findings were similar to the study done by Eric et al. (2017) ${ }^{(20)}$ who found that majority of study sample were female and the mean age of participants was 21.6 years.

The result of the current study revealed that majority of them were live in rural area, not working, have sufficient income, single and stable family status. This is might be due to the geographical location of Benha university it is near from the rural areas and the rural community maintains its children by living close to their families and responsible for them. This result similar with Bizri et al.(2021) ${ }^{(21)}$ who found that The majority of respondents living at home with their parents and only one student was married. On the contrary, this finding inconsistent with Maria et al. (2018) ${ }^{(22)}$ found that that majority of them were live in urban and working.

Regarding to studied students favorite sport, the result of the present study illustrated that nearly half of the students were walking as the favorite sport. This may be due to they are in rural areas and they do not have clubs to exercise, so the available to them is walking. This result inconsistent with Hewes (2018) ${ }^{(23)}$ who found that the studied female were asked to participate: basketball, crew, cross country, golf, lacrosse, soccer, swimming and diving, tennis, track and field, and volleyball. 
Concerning to mean and standard deviation of the students regarding height, weight and body mass index were

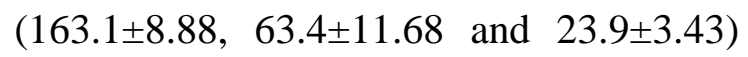
respectively. This result agreement with Akesode and Ajibode (2018) ${ }^{(24)}$ who found that the height of the study sample were $160 \pm 5.8$ and weight were $60.61 \pm 4.1$ and similar with Bardone-Coneet al. ( 2019) ${ }^{(25)}$ who found that the mean body mass index of participants was $22.3 \pm 3.8$ ). Also, this finding congruent with Atanasova et al.(2018) ${ }^{(26)}$ who found that mean height of the students males $181,33 \pm 8,31$,females- $168,45 \pm 8,22$; mean weight of the students males $76,93 \pm 11,81$, females- $60,95 \pm 10,22$; mean of the students body mass index ( BMI) males- 23,4 $\pm 2,95$, females- $21,4 \pm 2,62$.

Regarding to studied students body mass index, the result of the current study demonstrated that, less than two-thirds of the students have normal body mass index while minority of them have obese. This may be due to students have intense fear of gaining weight of becoming fat and, recurrent inappropriate compensatory behavior in order to prevent weight gain. In addition, eating pathology increases the risk for future onset of obesity, anxiety disorders and health problems.. This finding was consistent with Hasseet al. $(2019)^{(27)}$ who found that majority of students have normal body mass index while minority of them have obesity. Furthermore, this result was consistent with Cunjian et al. (2019) ${ }^{(28)}$ who revealed that Children and adolescents in China's Xinjiang Uyghur Autonomous Region with a normal body mass index demonstrated good physical fitness.

Concerning to studied students total perfectionism, the result of the present study showed that, less than two-thirds of the students have moderate perfectionism perfectionism has increased dramatically among young people, leading to negative. This may be due to Perfectionism can be general, which is when someone has the broad tendency to have unrealistically high standards, or it can occur in specific aspects of life, such as in work or school performance, relationships, writing, speaking, athletics, health, personal cleanliness, or physical appearance. also, This may be due to side effects such as eating disorders and depression. This finding inconsistent with Katherine et al. (2018) ${ }^{(29)}$ noted that the healthy comparison subjects had slightly lower scores on all subscales of the Multidimensional Perfectionism Scale than previously reported normative data from a female college population.

Regarding to studied students for anorexia nervous and bulimia nervosa, the present 
study revealed that, more than half of the students have moderate anorexia nervous while two thirds of them have bulimia nervosa. This may be due to anorexia nervous (AN) is characterized by a refusal to maintain a minimally normal body weight, an intense fear of gaining weight or becoming fat, and a disturbance in the experience of body shape or weight. Also, Overweight girls are more likely to engage in unhealthy dieting behaviors, express concern about their weight, restrain their eating, and to have greater dissatisfaction regarding their physical appearance than their average-weight peers. This result similar to the study done by Godart et al. (2020) ${ }^{(30)}$ who found that most of subjects with Anorexia nervosa and two thirds of those with Bulimia nervosa had at least one lifetime diagnosis of an anxiety disorder. On the contrary, this result is incongruent with Smink et al. (2020) ${ }^{(31)}$ who found that Anorexia nervosa is relatively common among young women; there has been an increase in the high risk-group of 15-19 year old girls. The occurrence of bulimia nervosa might have decreased since the early nineties of the last century.

The current study showed that, more than half of the students have moderate eating disorders. This may be due to nursing students are subjected to high levels of stress and have a high risk of developing mental health problems, including eating disorders., it is plausible that disordered eating behaviors among students may go unrecognized and under-reported. This result similar with Kobeissy \&Talih(2021) ${ }^{(32)}$ who found that the study subjects seems to be a high level of under recognized and under-treated disordered eating behaviors among female medical students at American University of Beirut.

Concerning to relation between total body mass index, total perfectionism and total eating disorders, the result of the current study showed that there were a statistically significant difference between total body mass index, total perfectionism and total eating disorders. This may be due to Perfectionism can cause a person to become obsessed with their weight, diet, food, body image, exercise or portraying the "perfect" image to the world. Also, Eating disorders are characterized by severe disturbances in eating behavior and body weight. Eating disorders are frequent in adolescents and even more in young adults. This finding in the line with Marianaet al. (2018) ${ }^{(33)}$ who found that, dysfunctional eating behaviors appeared to correlate strongly and significantly with body mass index, perfectionism dimensions, and self-esteem. Also, this result congruent with Hudson et al. (2018) ${ }^{(34)}$ who stated that Lifetime anorexia 
nervosa is significantly associated with low current weight (body-mass index <18.5), whereas lifetime binge eating disorder is associated with current severe obesity (body-mass index $>$ or $=40$ ).

Regarding to relation between total perfectionism and socio-demographic characteristics of studied students, the result of the current study illustrated that, there was statistical and highly statistical significant difference between total perfectionism and socio-demographic characteristics such as sex, residence, family income and marital status while no statistical difference between total perfectionism and age, family status. This may be due to perfectionism interferes with close, interpersonal relationships and perfectionists have been described as people who want to be perfect in all domains of their lives. Moreover, perfectionists selected the type of work they liked best and were best fitted to do and as this group of people was all thrifty and industrious, they became comparatively wealthy. This result in the line with Cemrenur and Füsun, (2019) ${ }^{(35)}$ who found that there were statistically significant difference among participants according to sex, major residence ,financial statuses and perceived parental attitudes. On the contrary, this finding was disagreement with Fusun, ( 2018) ${ }^{(36)}$ As a result of research, perfectionism scores of the preschool teachers are significantly different according to their demographic characteristics such as age, graduation degree, school type and professional experience at the present institution.

Concerning to relation between total eating disorder and socio-demographic characteristics of studied students, the present result illustrated that, there was statistical significant difference between total eating disorders and sociodemographic characteristics such as sex and marital status while no statistical difference between total eating disorders and age, residence, family income and family status. This may be due to, Eating disorders are an increasingly prevalent public health problem among adolescents and young women. Also, images of women in the media and popular culture apply considerable pressure to be thin on vulnerable young girls and women, for whom it is difficult to live up to these expectations, regardless of their natural body shape. This result similar with Galmiche et al. (2019) ${ }^{(37)}$ concluded that despite the complexity of integrating all eating disorder prevalence data, the most recent studies confirm that eating disorders are highly prevalent worldwide, especially in women. 
Finally an important finding from the current study revealed that there was highly positive Correlation between total eating disorder and total perfectionism. This may be due to eating disorders are characterized by high-level perfectionism which endures after recovery and appears to be familial in nature and to have pre dispositional significance for the development of eating disorders. And due tothe emergence of perfectionism may be a consequence of an eating disorder. This result agreement with Cynthia et al. (2018) ${ }^{(38)}$ we found that elevated scores on a perfectionism scale-especially the aspects of perfectionism captured by the subscale for concern over mistakes-were significantly associated with the presence of eating disorder such as anorexia nervosa and bulimia nervosa. Also, this result in the same line with Canals et al. (2019) ${ }^{(39)}$ found that in their study the father's perfectionism were related to long-term Eating Disorder. Moreover, these findings were similar to the study done by Vacca et al. (2021) ${ }^{(40)}$ we found that there were highly statistically significant relation between perfectionism and eating related symptoms in adolescents .

\section{Conclusion}

The highest percentage of the studied students have moderate perfectionism, while more than half of the studied students have moderate eating disorders. Also, there were a statistical significant difference between total body mass index, total perfectionism and total eating disorders. In addition there was highly positive correlation between total eating disorder and total perfectionism.

\section{Recommendations}

Based on the findings of the current research, the following recommendations are suggested:

- Expand public awareness through mass media about perfectionism and its effect on eating disorder among university students.

- Designing program focused on unrealistic standards of beauty to reduce adolescent's criticism body weight and shape.

- Further studies are needed on large sample of students in different geographical areas to generalize the results.

\section{References}

1. Yang A, Hongfei E, Stoeber A. Joachim M. "The Physical Appearance Perfectionism Scale: Development and Preliminary Validation" (PDF). Journal of Psychopathology and Behavioral Assessment.2021; 34 (1): 69-83.

2. Curran A, Thomas H, Andrew $\mathrm{P}$ "Perfectionism is increasing over 
time: A meta-analysis of birth cohort differences from. 2019; 50(3):99-105.

3. Klump K, Bulik C, Kaye W, Treasure J, Tyson E. Academy for eating disorders position paper: Eating disorders are serious mental illnesses. Int J Eat Disorder. 2018; 42(3):97-103.

4. Ternouth A, Collier D. Eating disorders and obesity: Two sides of the same coin? Epidemiol Psychiatry Soc. $2019 ; 18: 96-100$.

5. Nolen-Hoeksma

A. Abnormal Psychology. 6th ed; US: McGraw-Hill. 2021; p. 339.

6. Yale E, Susan B, Nolen-Hoeksema A. Abnormal psychology. 6th ed. New York, McGraw

Hill Education.2020;340-341.

7. Rikani A, Choudhry Z, Choudhry A, Ikram H, Asghar M, Kajal $\mathrm{D}$, Waheed A, Mobassarah N. A critique of the literature on etiology of eating disorders. Annals of Neurosciences;2020; 20 (4): 157

8. Arcelus J, Witcomb G, Mitchell A. "Prevalence of eating disorders amongst dancers: a systemic review and meta-analysis". European Eating Disorders Review.2020;22 (2): $92-$ 101.

9. Hoerr L, Bokram R, Lugo B, Bivins T, Keast D. Risk for disordered eating relates to both gender and ethnicity for college students. J Am CollNutr.2018;21:307-314.

10. Calado M, Lameiras $\mathrm{M}$, Sepulveda R, RodrÃguez Y, Carrera M. The mass media exposure and disordered eating behaviours in Spanish secondary students. European Eating Disorders Review .2021, 18(5), 417-427.

11. Serrao H. Competitiveness and addictive behaviors: Exploring the role of competitiveness and gender in exercise dependence, disordered eating, and alcohol use. Dissertation Abstracts International $.2021 ; 71$.

12. Muhlheim L. Perfectionism in Eating Disorders. Psychological Bulletin, 145(4), p: 139Prevalence of eating disorders over the 2000-2018 period: a systematic literature review, American Journal of Clinical Nutrition.2021; 109(5):1402-1413.

13. American

Psychiatry Association. Diagnostic and Statistical Manual of Mental Disorders. 5th ed. Arlington: American Psychiatric Publishing.2018; 329-354.

14. Smink F, Van A, Hoeken D, Hoek H. Epidemiology, course, and outcome of eating disorders. Current 
Opinion in Psychiatry.2019;26 (6): 543-8.

15. Behar R. Gender identity and eating disorders:

psychosocial perspective. In K. Yip, K. Yip (Eds.), Psychology of gender identity: An international perspective (pp. 193-215). Hauppauge, NY US: Nova Science Publishers;.2020. ; 45(2):91-95..

16. Pike M, Hoek H, Dunne P. Cultural trends and eating disorders. Current Opinion in Psychiatry;.2021;27(6): 436-42

17. Hewitt L, Flett L, Turnbull-Donovan W, Mikail F. The Multidimensional Perfectionism Scale: Reliability, validity, and psychometric properties in psychiatric samples. Psychological Assessment: A Journal of Consulting and Clinical Psychology.1991; (3), 464-468.

18. Mohammad S. The Relationships Among Perfectionism, and Eating Disorders to a Sample of University Students. Faculty of Education, Benha University , Egypt.2015 .

19. Fairburn G, Cooper Z, Shafran R. Cognitive behavior therapy for eating disorders: A "trans diagnostic" theory and treatment. Behav Res Ther.2018; 41:509-528.
20. Eric S, Melissa F, Erin M. Eating Disorder Diagnostic Scale: Additional Evidence of Reliability and Validity, American Psychological Association .2017;16(1) 60-71.

21. Bizri M, Geagea L, Kobeissy F, Talih F. Prevalence of Eating Disorders Among Medical Students in a Lebanese Medical School: A CrossSectional Study, Neuropsychiatric Disease and Treatment; 2021; (16) ; 1879-1887.

22. Maria T, Ana P, Mariana M, Jorge S, António M. Eating behaviors, body image, perfectionism, and self-esteem in a sample of Portuguese girls. Bras. Psiquiatr.2018; 38 (2) ; 135-140.

23. Hewes R. Perfectionism as a Predictor of Eating Disorder Symptoms: A Comparative Study of Female College Athletes and Non-athletes. Open Access Dissertations.2018. , 45 (3) ;85.

24. Akesode F, Ajibode A. Prevalence of obesity among Nigerian School Children. Social Science \& Medicine. 2018; 17(2):107-11

25. Bardone-Cone A, Wonderlich A, Frost O, Bulik M, Mitchell E, Uppala S. Perfectionism and eating disorders: Current status and future directions. Clinical Psychology Review.2019;27, 384-405. 
26. Atanasova V, Gatseva B, Bivolarska A, Fronas G. Body mass index and food frequency intake of foreign medical students. Trakia Journal of Sciences.2018; 12, (1); 367370.

27. Hasse A, Prapavessis H, Owens G. Domain-specificity in perfectionism: Variations across domains of life. Personality and Individual Differences.2019. , 40 (2) ;90.

28. Cunjian B, Junmin Y, Jian S., Song X, Feng Z. Benefits of normal body mass index on physical fitness: A cross-sectional study among children and adolescents in Xinjiang Uyghur Autonomous Region, China. Current Psychiatry Reports.2019 14(4):406-41.

29. Katherine A, Halmi M, Suzanne R, Michael S, Alan K. Perfectionism in Anorexia Nervosa: Variation by Clinical Subtype, obsessionality, and Pathological Eating Behavior Psychiatry.2018;157:1799-1805.

30. Godart T, Flament F, Lecrubier Y, Jeammet P. Anxiety disorders in anorexia nervosa and bulimia nervosa: co-morbidity and chronology of appearance .2020; ( 1$) ; 38-45$.
31. Smink F, Daphene H, Hoek W. Epidemiology of eating disorders: incidence, prevalence and mortality rates. Current Psychiatry Reports.2020, 14(4):406-41.

32. Kobeissy F, \& Talih F. Eating Disorders Among Medical Students in a Lebanese Medical School: A CrossSectional Study, Neuropsychiatric Disease and Treatment »;2021, 50 (3) ;100.

33. Mariana M, Jorge S, António M. Eating behaviors, body image, perfectionism, and self-esteem in a sample of Portuguese girls. Bras. Psiquiatr.2018, 54 (3) ;150.

34. Hudson J, Hiripi E, Pope H, Kessler R. The Prevalence and Correlates of Eating Disorders in the National Co morbidity Survey Replication, ,Biological Psychiatry.2018, 61(3):348-58.

35. Cemrenur T, Fusun Y. The study of teacher candidates' perfectionism in relation with achievement and demographics, Procedia - Social and Behavioral Sciences.2019, 152; 121 126.

36. Fusun Y. The Study of Preschool Teachers' Perfectionism Levels in Relation with Demographic Variables, Procedia Social and Behavioral Sciences.2018; 152;116- 120 . 
37. Galmiche M, Déchelotte $P$, Lambert G, Tavolacci M. Prevalence of eating disorders over the 2000-2018 period: a systematic literature review, American Journal of Clinical Nutrition .2019,109(5):1402-1413.

38. Cynthia M, Bulik F, Tozzi C, Suzanne E, Steve A, Patrick F. The Relation between Eating Disorders and Components of Perfectionism, Psychiatry. 2018, 160;:366-368.

39. Canals J, Sancho C, Arija M. Influence of parent's eating attitudes on eating disorders in school adolescents, European Child and Adolescent Psychiatry, Springer Verlag (Germany).2019;18 (6) ;353-359.

40. Vacca M, Ballesio A, Lombardo C. The relationship between perfectionism and eating- related symptoms in adolescents: A systematic review, European Eating Disorders .2021;29(1); 32-51. 